being no perforations or lacerations. The coaptation of parts was perfect. The nares were packed with aseptic gauze holding the parts well together; packing was removed in forty-eight hours; parts looked healthy. The patient did well for four days, on the fifth day the septal wall looked bad, and a day or two later the entire septal wall in site of operative field sloughed, leaving a large perforation. At this time a swelling in the nasopharynx was discovered. I was at a loss to account for this condition. Suspecting that latent syphilis might be present I had a Wassermann test made, which was negative. Nevertheless I put him on a mixed treatment and asked for consultation. Two specialists in rhinology saw him with me, and notwithstanding the history and negative Wassermann concurred in the opinion that the condition was one of tertiary syphilis and advised appropriate treatment. Under full doses of mercuric iodid and potassium iodid saturated solution, in increasing doses, up to 35 grains three times a day, there was rapid improvement in his condition. Wound healed nicely, the general health was better and case soon cleared up. The patient gained in weight and strength and said he never felt better.

Dr. Norval Prerce, Chicago: I have operated on syphilitic noses and have had just as good results as in the nonsyphilitic cases. I do not mean that we should operate in the presence of active syphilis. I had one patient, a young woman, unmarried, anemic, undoubtedly virtuous, who had recurrent hemorrhages from the nose. The epistaxis was due, as I thought, to a deflection of the septum; there was an erosion of the septum on one side. After the deviation was corrected everything went all right until about a week after the operation when she had a violent hemorrhage from the nose which came from some point well back and was very profuse. The nose was packed, the hemorrhage ceased and the patient recovered. A short time after that she came into the hands of Dr. Webster suffering from menorrhagia. He eventually performed a hysterectomy and found, on section of the uterus, a marked endarteritis. He informed me that there had been two Wassermann tests, both positive. I believe hemorrhage from the nose in children is suspicious. I have had recently two cases of ordinary epistaxis, in one of which, knowing the father to be a man of very liberal habits in his youth, I had a Wassermann done, and while he had no symptoms of syphilis, there was a marked positive reaction in the child. May not these be cases of syphilitic endarteritis very often? I think, however, it should not go forth from this section as our opinion that we should have a Wassermann test before every nasal operation.

DR. L. W. Jessaman, Framingham, Mass.: I reported a case in a colored woman with sinus trouble seen three years ago, in which no history of syphilis could be obtained. A few days later the patient developed a swelling at the inner canthus of the right eye and a diagnosis of ethmoiditis was made. She was operated on, the ethmoid cells cleared out and the patient did well until some time afterward when she returned with a swelling at the lower margin of the left orbit, and another on the right side of the nose below the lower margin of the orbit. A diagnosis was then made of gumma, and the condition was very quickly relieved with the administration of mercury and potassium iodid.

Dr. Dunbar Roy, Atlanta: In my clinic in the South I have a great many negroes, and syphilitic manifestations in the nose and throat in this class are very prevalent. The northern men hardly know what these manifestations are until they have seen these cases in the South. You can find the lesions from the nose down to the epiglottis, but I rarely ever see a gummatous condition in the larynx. I never find the epiglottis entirely ulcerated away. Another point I would call attention to is to have a Wassermann test made in the cases of vasomotor rhinitis that come to us. In three out of ten such cases of engorgement of the nose, I have found a late secondary manifestation of syphilis. I always have a Wassermann made in these cases and it is surprising how they will yield to antisyphilitic treatment. I believe in a large number of these cases there is a syphilitic basis.
Dr. Emil Mayer, New York City: A woman came to see me with the story that she had been under the care of some of our best physicians and that they had diagnosed a condition of gall-bladder trouble. She wanted me to give her the address of another man to consult, and said, incidentally, "I have a little sore in my nose. Would you look at it while I am here?" I made a nasal examination and said, "I think you will find the whole cause of your trouble due to this condition in the nose." İ sent her for a Wassermann test and, as I suspected, it was positive.

Dr. Joseph C. Beck, Chicago: I hope I did not give the impression that $I$ think it is necessary to have a Wassermann test in every case of nose or throat operation; only in suspicious cases in which the findings are not definite of lues.

DR. C. R. C. Borden, Boston: Someone has taken the ground that I overestimate the importance of latent syphilis. Last week at the meeting of the Laryngological, Otological and Rhinological Society I was asked how I dared etherize a patient who had acute congestion of the kidneys. I would have much less fear of such a kidney complication than I would in operating on a patient with latent syphilis in a delicate organ of special sense. In answer to Dr. Bernstein, doubtless a great many nose and throat operations have been performed with splendid results with no trouble from active or latent syphilis. On the other hand, serious complications have been known to follow in a sufficient number of cases as a result of syphilis to make it worth while to use proper precautions in all serious cases. I hope I have not given the impression that I have much faith in the Wassermann reaction, for $I$ have not. I went through a great deal of trouble to get the latest ideas of the leading Boston syphilographers on the subject under discussion in order that $I$ might present the other methods of diagnosis which are available for syphilis. Taking the subject as a whole, I appreciate the fact that it is not possible to have a routine Wassermann in every case, but all the larger hospitals are rapidly coming to it. We must consider that syphilis is a wide-spread disease and one which is the real cause underlying many diseased conditions in every field of medicine. Of course, in private practice, it would be impossible to have a routine Wassermann in every case, but in operations which are very destructive or mutilating a Wassermann test should always be done first. In fact, in my own experience, the procedure of the Wassermann reaction has more than once made such operations unnecessary.

\section{A NEW METHOD OF REFLEX ELICITATION}

PRELIMINARY REPORT *

WALTER B. SWIFT, M.D. BOSTON

After completing four or five researches on different phases of reflex action during which some two thousand observations were made, and after seeing several diagnoses made wrongly on what seemed to be misinterpreted or insufficient reflex data, I came to the conclusion that there was a crying need of a more efficient mode of reflex elicitation available for application in exceptional cases.

I tried first to improve present methods of elicitation. To that end I visited Jendrassik in Budapest and obtained personal instruction as to his method of applying the hand-grasp. I put this into practice in many cases at the Boston City Hospital and when I found his technic an improvement over our own I

* From the Neurological Department of Boston City Hosjital, Service of Prot. John Jenks Thomas.

* Read before the Section on Nervous and Mental Diseases at the Sixty-Fifth Annual Session of the American Medical Association, Atiantic City, N. J., June, 1914. 
published the results. ${ }^{1}$ Innumerable attempts to improve old methods met with failure. Then I began to search for some entirely new avenue of approach. I felt the need of another method not only for its worth in clinical routine examination, but also to enhance the value of my researches in reference to reflex frequency, ${ }^{2}$ and other reflex propositions not as yet published.

Therefore a series of reflexes were tried during and after the passage of the electric currents-galvanic and faradic. My sincere appreciation is due to Dr. John J. Thomas for opportunity to carry on this research at the Boston City Hospital. Minutely the problem was as follows:

\section{THE PROBLEM}

Galvanism and faradism, strong and weak currents, were passed in cases of normal, exaggerated, pathologic and absent reflexes. Although this research is still in process, sufficient positive data of value have been obtained to warrant the presentation at this time of several new facts in the form of a preliminary report.

A. I find that with weak faradic curient, normal refi.xes change as follows:

The Triceps: Unchanged in 3 cases. Made more pronounced in 3 cases.

Wrist: Unchanged in 2 cases. More pronounced 2 cases.

Radial: Unchanged 3 cases.

Biceps: Unchanged 1 case. More pronounced 2 cases.

Knee-Jerk: Unchanged in 4 cases. More pronounced in 2 cases.

Achilles: Unchanged 2 cases. More pronounced 2 cases. Plantar: Unchanged 2 cases.

B. I find that with weak faradic current, exaggerated reflexes change as follows:

Triceps, Wrist, Radial, Biceps: Unchanged 1 case each.

Knee-Jerk: More pronounced exaggeration in 3 cases.

Achilles: Unchanged 1 case.

One case showed leg clonus on patella tap, when without electricity both knee-jerks were merely exaggerated.

C. With weak faradic current, not enough cases were tried to tabulate any pathologic reflexes.

D. I find that with mild faradic current, absent reflexes clianged as follows:

In one case of multiple neuritis, knee-jerk pronounced absent by every other method of reenforcement clearly elicited with weak faradic current and just after the current had passed.

In one case of anterior poliomyelitis (?) right Achilles pronounced absent by Dr. Thomas with usual methods of reenforcement. Found later to be absent because tired out. Obtained, however, after being tired out during the passage of a mild faradic current. Came about every other trial. Also found occasionally present after the current had passed and was again cut off. (Dr. Daly's observation.)

In one case of paresthesia of hand, knee-jerk reported absent on both sides with all other methods of reenforcement but obtained in mild faradic current on both sides. In the same case the right Achilles pronounced absent but elicited with a mild faradic current, a mild galvanic current, and a strong galvanic current.

Had there been but one positive case, had electricity only once elicited a reflex not obtainable by any other method of elicitation, it would have been worth reporting. But here are several.

1. Swift, Walter B.: Studies in Neurological Technique No. 1: The Points in Jendrassik's Method of Eliciting the Patella Reflex, Alienist and Neurologist, 1913, xxxiv, No. 3

2. Swift, Walter B.: Reflex Frequency and Its Clinical Value, Jour. Nerv. and Ment. Dis., 1913, xl, No. 9.

\section{CONCLUSIONS FROM THESE FINDINGS}

From some 46 tests of the reflexes during the passage of the electric current, including normal, exaggerated, pathologic and absent reflexes, the phenomena show the following data:

1. Normal reflexes are made more active in about half the cases examined.

2. Exaggerated reflexes are unchanged in the arm, made more pronounced in the leg with exception of the Achilles.

3. Not enough pathologic reflexes were tried to warrant any conclusion.

4. Absent reflexes are generally unaffected but are sometimes elicited with this method when all other methods have failed. Applicable to the knee-jerk and Achilles.

\section{COMMENT}

That the electric current enhances the normal kneejerk has no clinical value; also that during the current exaggerated reflexes become more exaggerated is of no great value. Whatever changes may be found in pathologic reflexes, and I predict here an increase, may contribute little. The fact of indirect value that they contribute to the situation is the general effect of electricity on general reflex action-the action of enhancing them-a fact that makes the findings under absent reflexes of more weight than if the opposite had been true. For if no increase of reflex action had been found in normal and exaggerated reflexes, we would be inclined to doubt such findings under absent reflexes, but finding they are increased in action when normal, and when exaggerated, we are still more inclined to expect that same action when the reflexes are absent by usual methods.

This finding of enhancement of them among normal and exaggerated reflexes lends momentum to the findings while the current is passing through otherwise absent reflexes.

Among absent reflexes the current occasionally elicits a reflex otherwise unobtainable. This is surely of some clinical value as a new and improved method of reflex elicitation.

Granted, many absent reflexes are pathologically absent and then no current can elicit them-as for example I have found in tabes-but there exist borderline cases-even cases in which absent or present may turn a diagnosis or markedly change a prognosis-and it is in these latent reflexes (that occasionally are so important to find), that this new method plays a service to neurologic routine examination in succeeding in demonstrating their elicitation.

\section{SUMMARY AND CLINICAL VALUE}

Examination of over forty cases of reflexes during and some after (Daly) the passage of the electric current demonstrates that the general effect of electricity on the reflexes is that of a reenforcement-which finds its special clinical value by elicitation of some of the absent reflexes unobtainable by any other method. I therefore claim a new method of reflex reenforcement of sufficient value to be included among other routine and neurologic examination methods in the following order: pendulum leg, diversion of mental attention, constant movement during stimulus, the Jendrassik hand-grasp, and finally, when all others fail, the electrical reenforcement.

Medical History.-Old sciences are unraveled like o!d stockings, by beginning at the foot.-Swift. 


\section{ABSTRACT OF DISCUSSION}

Dr. J. T. Fisher, Los Angeles: Dr. Swift is to be congratulated on discovering a method of eliciting a lost reflex. I would like to have him explain a little more in detail the technic of the procedure, and would ask, in addition, if we are to understand that when the knee-jerk is gone, lost forever, as we see in cases of well-advanced tabes, he can reproduce that reflex by the method which he uses, or whether he has reference merely to the lost reflex which sometimes does occur in functional cases due to overfatigue of the reflex arc by the ordinary method of taking a reflex.

Dr. William W. Graves, St. Louis: We need, of course, anything in clinical work which will aid in determining the functional activity of the nervous system, and among its activities, those pertaining to reflexes are of the first order. Until it is a uniform practice to guard against the pitfalls in the use of reflexes, we shall not be able to use all of the refinements in examinations. I did not understand whether it was during the attempt to elicit a given reflex-the knee-jerk, for instance-that the electric current was passed, and whether it was assumed that the stimulation served as a means of increasing the excitability of the reflex arcs, or whether the use of the current was merely a means of suddenly diverting the patient's attention. I would ask Dr. Swift to explain these points in closing.

Dr. Walter B. SwIFT, Boston: Dr. Fisher asked about the technic in eliciting the knee-jerk. I put one electrode under the leg of a sitting patient and the other one on the calf. In eliciting the Achilles tendon reflex I put one electrode on the calf and one on the sole of the foot. I find it does not make any difference which electrode is put above and which one below. Dr. Fisher also asked about the type of the reflex that I attempted to bring out. I agree with the suggestion made by Dr. Fisher that the absolute pathologically broken arc can not be revived in its function, and that the lost reflexes of tabes and other pathologic lesions when the arc, either of the motor side or of the sensory side, is entirely gone, cannot be brought out by this method. This will perhaps also answer Dr. Graves' question: It is applicable in border-line cases; that is, those in which other methods have failed to elicit a reflex, and in an arc that is intact. In cases in which our diagnosis turns more or less on the absence or presence of a reflex, and in which it is found impossible to elicit those reflexes by our usual methods of reinforcement, this is a final resort. I would not by any means propose that this should be a matter of usual routine in neurologic examinations. I think that is entirely out of the question; but I do think that it is of value in rare cases and in borderline cases when other methods of elicitation have failed, and that I have found in the clinic of the Boston City Hospital in these cases that I have reported. Dr. Graves asked about the effect of the electricity. The reflex is taken with the current on; that is, the current is started and the reflex is taken during the passage of the current. He also asked whether it was the effect of the current that elicited the reflex, or the diversion of the attention. From the fact that the reflex has, also been obtained after the current has passed and after the electrodes have been removed I would be inclined to give the credit to the passage of the electricity, especially as these cases have failed to show reflexes when other methods of diversion of the attention have been employed.

The Duty of Research in the University.-Wonderful as were the isolated achievements of the great discoverers in medicine in the early centuries, the great continuous advance in medicine during the past eighty years resulted from organized laboratory effort based on the principle of exact experimental methods; and it is the duty of the university so to organize its laboratories and hospitals that this advance of medicine by research may continue, side by side with teaching, as a university function of benefit to students and faculty as well as to the state and the general public welfare, and thus as an aid to the advancement of civilization.Richard M. Pearce.
FOUR CASES OF SUDDEN DEATH

\section{IN A SILO}

E. R. HAYHURST, M.D.

Director, Division of Occupational Diseases, Ohio State Board of Health

AND

ERNEST SCOTT, M.D.

Professor of Pathology, Ohio State University, College of Medicine

COLUMBUS, OHIO

In view of the constantly increasing importance of the silo for the preservation of fodder on the American farm, it seems proper to draw widespread attention to the danger of fatal asphyxia which may occur to workers in filling and emptying silos. There are no reported cases on record of fatalities under such circumstances so far as we have been able to learn after a careful search of the literature. Agricultural bulletins ${ }^{1}$ wain of the danger of carbon dioxid asphyxia unless certain precautions are taken. A sudden death here and there has unquestionably been laid to heart failure, apoplexy and the like.

Since the first American silo was built by Dr. Manly Miles, ${ }^{2}$ in 1875, the principle has undergone widespread development throughout the country so that the dangers herein cited are liable to beset a large number of persons. The danger from the accumulation of heavy gases in the old type of pit-silos dug in the ground can be easily appreciated, but the instances in question took place in a modern upground metal silo, built about 40 feet high, and free from surroundings which might interfere with ventilation.

At the Athens (Ohio) State Hospital, at about 7 o'clock on the morning of Sept. 19, 1914, four members of a squad of six men ascended the ladder on the outside of the silo in question to an open door about 12 feet from the top, and jumped in, one after the other, on the silage, the level of which was about 6 feet below the doorway. Within five minutes, as reported, the next two men who ascended shouted down that the first four looked as though they were dead. A large force of workers who were at hand immediately ascended the silo, and opening a lower door which was just above the level of the silage, hurriedly removed the unconscious forms, and, in spite of the immediate arrival of four or five physicians from the institution, all attempts at resuscitation failed.

The unfortunate ones, one of whom was 31 years old, and the others 56, 56 and 67, were "trusties" at the institution, and all had been engaged for several years on the institutional farm, and had helped in filling silos for the past two or three years. During the two weeks previous they had helped to fill two large wooden silos nearby, and during the three days previous had helped with the filling of the metal silo in question. Their work was to tramp down the ensilage as it was delivered from the blowpipe. On this morning the machine had not yet begun operations, and apparently the men sat down or lay down on the silage to wait.

To expedite the removal of the victims they had to be let down head first within the $31 / 2$-foot chute which

1. Babcock, S. M., and Russell, H. L.: Causes Operative in the Production of Silage, 17th Ann. Rep., Wisconsin Agric. Expt. Sta., 1900, p. 131. Crisp, H. L., and Patterson, H. J.: Silos and Silage in Maryland, Bull. 129, Maryland Agric. Expt. Sta., July, 1908, p. 10. Erf, Oscar: The Silo for the Dairy, Bull. Agric. Coll., Farmers' Reading Course, Vol. 2 , No. 4, Ohio State Univ., p. 3. 